\title{
Fibre intake and evolution of BMI: from pre-pregnancy to postpartum
}

\author{
Michele Drehmer ${ }^{1, *}$, Suzi Alves Camey ${ }^{1,2}$, Maria Angélica Nunes $^{1}$, Bruce B Duncan ${ }^{1}$, \\ Mauro Lacerda ${ }^{2}$, Andréia Poyastro Pinheiro ${ }^{1}$ and Maria Inês Schmidt ${ }^{1}$ \\ 'Graduate Studies Program in Epidemiology, Department of Social Medicine, Federal University of Rio Grande \\ do Sul, Rua Ramiro Barcelos no. 2600 - $4^{\circ}$ andar - sala 419, CEP 90035-003, Porto Alegre, RS, Brazil: \\ ${ }^{2}$ Department of Statistics, Institute of Mathematics, Federal University of Rio Grande do Sul, Porto Alegre, \\ RS, Brazil
}

Submitted 4 March 2012: Final revision received 25 June 2012: Accepted 12 July 2012: First published online 24 August 2012

\begin{abstract}
Objective: To evaluate the effect of fibre intake on the evolution of maternal BMI from pregnancy to postpartum and to identify dietary patterns associated with fibre intake.

Design: Cohort study. Food intake was obtained using an FFQ. Focused principal component analysis was used focusing on the variables: postpartum weight retention and total dietary fibre intake. Poisson regression models with robust variance were built in order to measure the effect of fibre intake during the postpartum period on obesity risk.

Setting: Primary care clinics in southern Brazil.

Subjects: Pregnant women ( $n$ 370) were followed until the 5th month postpartum.

Results: The highest contribution to fibre intake came from the consumption of beans. Consumption of bread and rice indicated a common Brazilian food pattern along with beans. Participants retained a median of $4 \cdot 4$ (interquartile range $0 \cdot 6,7 \cdot 9$ ) $\mathrm{kg}$ of weight gained during pregnancy. Obesity risk, defined as an unfavourable evolution of BMI during pregnancy and postpartum, was present in $189(55 \cdot 1 \%)$ women. Individual food items did not have an important effect on weight retention. In Poisson regression adjusting for maternal age, pre-pregnancy BMI and total gestational weight gain, inadequate postpartum fibre intake increased obesity risk by $24 \%$ (relative risk $=1 \cdot 24 ; 95 \%$ CI $1 \cdot 05,1 \cdot 47$ ).

Conclusions: Important maternal weight retention occurred in these women. Adequate fibre intake may reduce obesity risk in the period following childbirth.
\end{abstract}

Keywords Postpartum BMI Fibre intake Maternal obesity
The postpartum period appears to be a critical period for obesity development in women of reproductive age due to maternal weight retention determined by a series of interrelated factors ${ }^{(1,2)}$. Gestational weight gain above the recommendations of the Institute of Medicine (IOM) is considered the most important predictor for postpartum weight retention, increasing the short-, medium- and long-term risk obesity ${ }^{(3-8)}$.

Among other factors associated with postpartum weight variation, maternal age, parity, social and demographic factors as well as pre-pregnancy nutritional status represent non-modifiable factors or ones that occur before pregnancy $^{(1,2)}$. Modifiable factors related to lifestyle, such as diet, physical activity, smoking and lactation, and their effects on the postpartum weight evolution, are still relatively underexplored in the literature ${ }^{(9-12)}$.

Maternal energy intake needs to be increased in both pregnancy and postpartum in order to meet physiological demands. The American Dietetic Association recommends that food intake in pregnancy and the postpartum period should be based on whole grains, fruit and vegetables, aiming at meeting recommended vitamin and mineral contents $^{(13)}$. Nutritional restriction is discouraged even for obese women in the postpartum period, and methods that emphasize a fast weight loss are not recommended ${ }^{(14)}$. Approximately $13-20 \%$ of women do not return to their pre-pregnancy weight, showing significant postpartum weight retention ${ }^{(15-17)}$. More than two-thirds of women face some degree of weight retention at 6 weeks postpartum $^{(18)}$. Postpartum maternal food recommendations are based on the needs to promote breast-feeding, but the best way to achieve the ideal maternal weight over the postpartum period is not clear ${ }^{(19)}$. The only international postpartum weight-loss recommendation is about $2 \mathrm{~kg} /$ month after the first month postpartum for women with low or normal pre-pregnancy $\mathrm{BMI}^{(14)}$. 
It is well known that a fibre-rich diet is related to weight control and obesity prevention ${ }^{(20-22)}$. Pregnant and postpartum women should have a higher fibre intake compared with the general adult population. The positive effects of fibre consumption for pregnant and postpartum women include promoting heart health and decreasing diabetes risk and constipation effects as well as reducing pre-eclampsia risks, together with providing nutrient-rich food with low energy density ${ }^{(13,23)}$.

For the population in general, convincing evidence exists demonstrating the protective effect of a fibre-rich diet against weight gain and a minimal daily fibre intake is recommended by the 'Global Strategy for Healthy Eating, Physical Activity and Health' of the $\mathrm{WHO}^{(24,25)}$. It is still not clear in the current literature whether the consumption of a fibre-rich diet could help prevent postpartum maternal weight retention. A recent finding points to a possible protective effect. Oken et al. describe that daily intake of fibre was associated with a protective effect on postpartum weight retention of $\geq 5 \mathrm{~kg}(\mathrm{OR}=0 \cdot 72,95 \%$ CI $0 \cdot 56,0 \cdot 94)^{(1)}$

Based on the aforementioned, the present study aimed to evaluate the effect of postpartum fibre intake on the change of maternal BMI from pre-pregnancy to postpartum, as well as to identify dietary patterns associated with fibre intake among women assessed in the 4th-6th month after childbirth.

\section{Methods}

\section{Study design and sample}

The ECCAGE Project (Study of Food Intake and Eating Behaviour of Pregnant Women; the acronym is derived from the study's Portuguese name of Estudo do Consumo e do Comportamento Alimentar em Gestantes) is a cohort study of pregnant women enrolled in primary health-care units of the Brazilian Unified Health System, and was conducted in the cities of Porto Alegre and Bento Gonçalves between 2006 and 2007. The cohort consists of three phases: (i) baseline (phase I), in which pregnant women between the 16th and 36th pregnancy week were consecutively enrolled in the study; (ii) the follow-up period immediately postpartum (phase II) during which information was obtained from medical records; and (iii) further follow-up between the 4th and 6th postpartum months (phase III). The present study refers to phase III, which included a convenience sample: sixty-one out of 311 women from Bento Gonçalves who were followed up in the 4th-6th month postpartum and 392 out of 401 women from Porto Alegre who were followed up in the 4th-6th month postpartum, for a total sample of 453 women.

In these phases, women had an evaluation of their current weight, as well as a retrospective evaluation of weight variation before, during and after pregnancy, in order to verify maternal weight retention and BMI evolution in the 4th-6th month postpartum. Additionally, a measurement of food consumption during the postpartum period was accessed by means of an FFQ.

In a previous paper, information regarding the methodology of all study phases was comprehensively described, including interview logistics, measurement of sociodemographic variables and maternal eating habits, weight and height measurements, and quality control ${ }^{(26)}$. The study flowchart is shown in Fig. 1.

Exclusion criteria were: twin pregnancy; lack of postpartum weight retention data; and implausible data for weight retention (below $-10 \mathrm{~kg}$ or above $20 \mathrm{~kg}$ ), daily energy consumption $(>25105 \mathrm{~kJ} / \mathrm{d})^{(19)}$ or daily consumption of fruits and vegetables, as standardized according to the Food Guide for the Brazilian Population $\left(>16\right.$ portions/d) ${ }^{(27,28)}$ (Fig. 1).

The study was conducted according to the guidelines laid down in the Declaration of Helsinki and all procedures involving human subjects/patients were approved by the Committee for Ethical Research of the Universidade Federal do Rio Grande do Sul, of the Health Center of Escola Murialdo and by the Municipal Health Departments of Porto Alegre and Bento Gonçalves. Informed consent was signed by all pregnant women who agreed to participate in the study.

\section{Main predicting variables -fibre intake and gestational weight gain}

An FFQ previously validated for pregnant women ${ }^{(29)}$ was used to evaluate food consumption. This instrument comprises eight consumption frequency options, varying from 'more than three times a day' to 'never or nearly never'. The list contains eighty-eight food items for which standardized portions of household measures or food units evaluating the consumed quantity are offered.

Estimates of fibre $(\mathrm{g} / \mathrm{d})$ and energy consumption $(\mathrm{kJ} / \mathrm{d})$, based on the FFQ, were obtained by summing estimates of fibre and energy consumption from each food, these being calculated as: consumption estimate $=$ consumption frequency $/ \mathrm{d} \times$ portion size $\times$ number of portions $\times$ (portion nutrient/portion size) ${ }^{(30,31)}$.

Determination of the quantity in grams of a standardized portion was done using the Brazilian Table for Evaluation of Food Consumption in Household Measurements $^{(32)}$. Food not contemplated in this table was weighed or measured in order to obtain a default value in grams. The Brazilian Food Composition Table ${ }^{(33)}$ was used as a reference to obtain the food's nutritional composition (energy value and value in grams, milligrams or micrograms of macro- and micronutrients). A second food composition table, the Food Composition Table: A Support for Nutritional Decision ${ }^{(34)}$, was consulted when any food appearing in the FFQ or any nutrient under investigation was not considered in the Brazilian Food Composition Table. Food labels were consulted only as a third option to obtain nutritional information. 


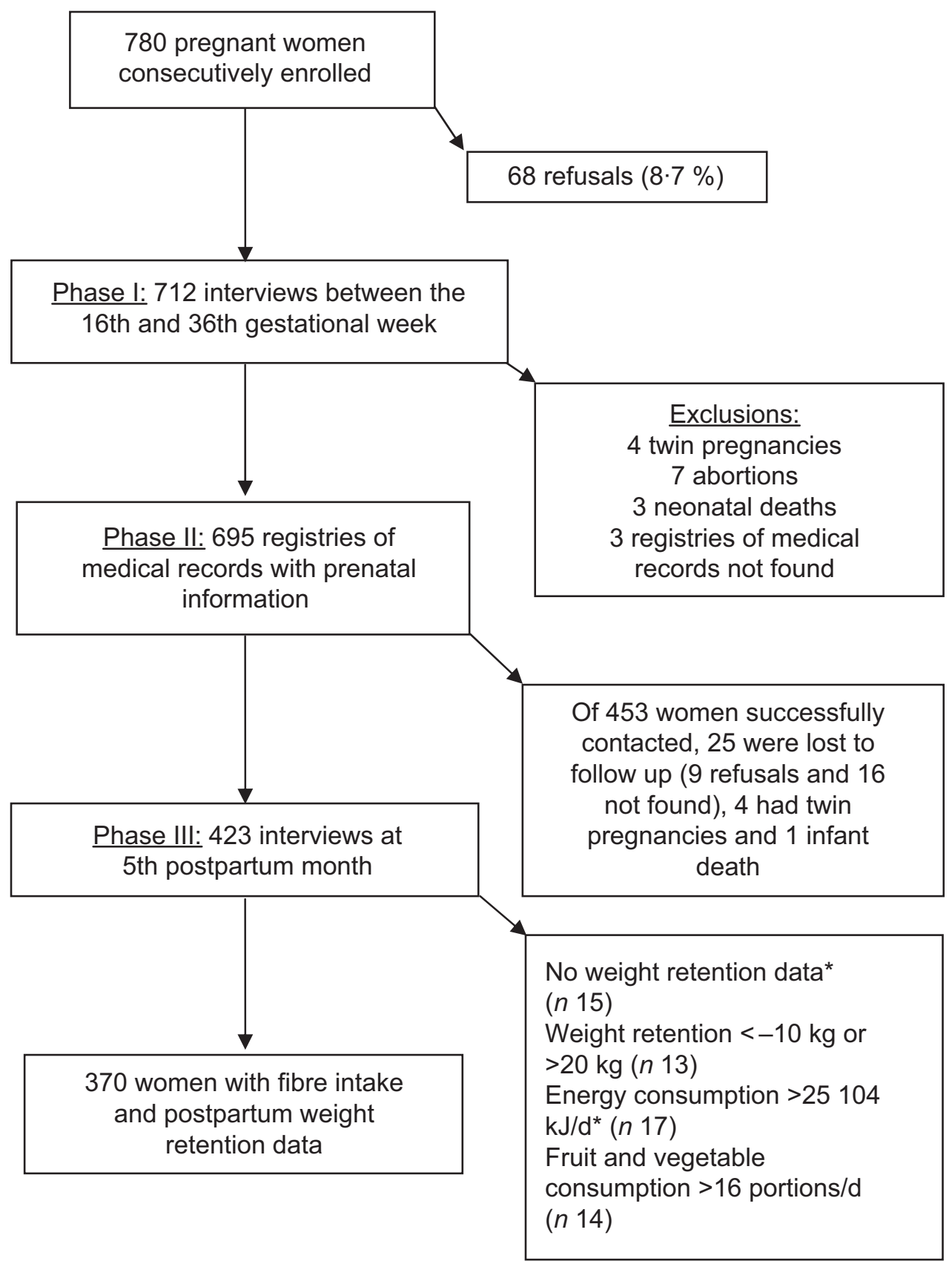

Fig. 1 Flowchart showing participants in the study. *Two excluded women were simultaneously without weight retention data and consumed $>25104 \mathrm{~kJ} / \mathrm{d}$ or $>16$ portions of fruits and vegetables/d; four excluded women simultaneously consumed $>25104 \mathrm{~kJ} / \mathrm{d}$ and $>16$ portions of fruits and vegetables/d

Food items were separated by food groups according to their description in the Food Guide for the Brazilian Population $^{(28)}$, permitting estimation of the number of portions of fruits and vegetables consumed daily.

In order to evaluate fibre intake adequacy at the 4th-6th month postpartum, the Adequate Intake recommendation of the Dietary Reference Intakes was used, which recommends consumption of at least $29 \mathrm{~g}$ fibre/d in the postpartum period. Women who were breastfeeding were classified as having 'reached' or 'not having reached' the recommendation of $29 \mathrm{~g}$ fibre $/ \mathrm{d}$. Mothers who were no longer breast-feeding were classified according to the Adequate Intake value for fibre recommended for adult women $(25 \mathrm{~g} / \mathrm{d})$. The same logic was used for the classification of maternal energy consumption adequacy. Since there are no Brazilian guidelines on intake of fibre during lactation, the American ones were employed ${ }^{(13)}$.

Total gestational weight gain was calculated as the difference between the weight at the end of pregnancy obtained from medical records (phase II) and the reported 
pre-pregnancy weight (phase I). Final pregnancy weight was considered as the last weight recorded at most two weeks before delivery. Pregnant women whose weight was not registered during the last two weeks before delivery had their values attributed using the simple imputation method, which is, multiplying the weekly weight gain average (adopting the first weight recorded from the second trimester as the basal component) by the number of weeks between the last weight registered during the prenatal period and childbirth. Pregnant women who had no weight registry beyond the 28th week were excluded. Further details regarding gestational weight gain were previously published ${ }^{(35)}$.

Total weight gain was classified according to the 2009 IOM recommendations. Total weight gain between 12.5 and $18.0 \mathrm{~kg}$ was considered adequate for women with pre-pregnancy BMI below $18.5 \mathrm{~kg} / \mathrm{m}^{2}$, between 11.5 and $16.0 \mathrm{~kg}$ for women with pre-pregnancy BMI between 18.5 and $24.9 \mathrm{~kg} / \mathrm{m}^{2}$, and between $7 \cdot 0$ and $11.5 \mathrm{~kg} / \mathrm{m}^{2}$ for women with pre-pregnancy BMI between 25.0 and $29 \cdot 9 \mathrm{~kg} / \mathrm{m}^{2}$. Total weight gain between $5 \cdot 0$ and $9 \cdot 0 \mathrm{~kg}$ was considered appropriate when pre-pregnancy BMI was higher than or equal to $30 \cdot 0 \mathrm{~kg} / \mathrm{m}^{2(9)}$.

\section{Outcome variable - weight retention and BMI evolution from pre-pregnancy to postpartum}

Participants reported their pre-pregnancy weight in phase I of the study. In phase III, weight was measured by a trained interviewer according to a standardized protocol $^{(26)}$. Weight retention $(\mathrm{kg})$ was defined as the difference between measured phase III maternal weight and reported pre-pregnancy weight.

The outcome - obesity risk - was defined to indicate an unfavourable evolution of BMI from pre-pregnancy to 4th-6th month postpartum. This risk was present with the following:

1. Change from a normal weight pre-pregnancy to overweight or obesity in postpartum;

2. Change from pre-pregnancy overweight to obesity in postpartum;

3. Change from class I obesity pre-pregnancy to class II obesity in postpartum;

4. Change from class II obesity pre-pregnancy to class III obesity in postpartum;

5. Weight gain among women who reported prepregnancy overweight or obesity but not enough to alter nutritional status in postpartum;

6. Weight loss among women who reported pre-pregnancy overweight or obesity but not enough to alter nutritional status in postpartum.

\section{Covariates}

The sociodemographic covariates were maternal age ( $\leq 19$ years, 20-29 years and $\geq 30$ years), years of schooling ( $\leq 4$ years, $5-8$ years and $\geq 9$ years), family income (expressed in minimum monthly wages, one minimum wage being equivalent to \$US $175 /$ month; categorized as $\leq 1$ minimum wage, $>1$ and $<3$ minimum wages and $\geq 3$ minimum wages), marital status (married, living with a partner, single/separated/divorced) and parity (primiparous and multiparous). Behavioural and nutritional covariates were also included in the following categories: smoking (smoker or non-smoker), breastfeeding (exclusive breast-feeding, non-exclusive and no breast-feeding), pre-pregnancy BMI (classification according to IOM 2009) and energy consumption (has reached or has not reached the recommendations according to the Dietary Reference Intakes). The postpartum follow-up was categorized into 'four months' and 'five to six months'.

\section{Statistical analysis}

Participants' characteristics were described by absolute and relative frequencies and Pearson's $\chi^{2}$ test was used to test the association with obesity risk. Continuous variables were described as mean and standard deviation, or median and interquartile range (IQR; 25th percentile, 75 th percentile), unless otherwise stated.

Focused principal component analysis (FPCA) was used to investigate the relationship between maternal weight retention and food consumption as well as the relationships among food items. This method was also used to investigate which foods had a stronger relationship with dietary fibre intake, as well as to characterize food patterns formed by the consumption of such foods ${ }^{(36,37)}$.

For the FPCA a list of nineteen selected foods items, among the eighty-eight listed in the FFQ, were correlated with fibre intake and with postpartum weight retention. Low-glycaemic-index foods, fibre-source foods belonging to the fruit and vegetable groups and the food items rice and bread were included because they were consumed at least twice daily by more than $50 \%$ of the sample. Foods not consumed by at least $75 \%$ of the sample were excluded.

In the FPCA, correlations are represented as concentric circles, in which circles with a smaller radius indicate stronger correlations. The outcome variable (fibre intake or postpartum weight retention) is listed at the centre of the circle. Positive correlations were plotted using $\bigcirc$ symbols and negative ones with $\bigcirc$ symbols. This analysis was carried out in the $\mathrm{R}$ program ( $\mathrm{R}$ Development Core Team, 2008) through the psy library ${ }^{(36)}$.

Poisson regression models with robust variance were built in order to measure the effect of fibre intake during the postpartum period on obesity risk. Adjusted models included covariates with $P \leq 0 \cdot 20$ in the univariate analysis. Covariates (age, schooling, monthly family income, parity, pre-pregnancy BMI, gestational weight gain, energy intake and postpartum follow-up time) were included as continuous variables in the multivariate model in order to increase power, whereby only variables with $P<0.05$ 
Table 1 Sociodemographic, behavioural and maternal nutrition factors in the postpartum period associated with obesity risk among women of two cities in southern Brazil ( $n$ 370), ECCAGE cohort study, 2006-2007

\begin{tabular}{|c|c|c|c|c|c|c|c|}
\hline \multirow[b]{3}{*}{ Variable } & \multicolumn{6}{|c|}{ Obesity risk* } & \multirow[b]{3}{*}{$P$ valuet } \\
\hline & \multicolumn{2}{|c|}{ Total } & \multicolumn{2}{|c|}{ No $(n 181 ; 48.9 \%)$} & \multicolumn{2}{|c|}{ Yes $(n 189 ; 51 \cdot 1 \%)$} & \\
\hline & $n$ & $\%$ & $n$ & $\%$ & $n$ & $\%$ & \\
\hline Age (years) & & & & & & & $<0.001$ \\
\hline$\leq 19$ & 87 & 23.5 & 66 & $36 \cdot 5$ & 21 & $11 \cdot 1$ & \\
\hline $20-29$ & 198 & $53 \cdot 5$ & 91 & $50 \cdot 3$ & 107 & $56 \cdot 6$ & \\
\hline$\geq 30$ & 85 & $23 \cdot 0$ & 24 & $13 \cdot 3$ & 61 & $32 \cdot 3$ & \\
\hline Schooling (years) & & & & & & & 0.060 \\
\hline $0-4$ & 48 & $13 \cdot 0$ & 16 & $8 \cdot 8$ & 32 & $16 \cdot 9$ & \\
\hline $5-8$ & 177 & $47 \cdot 8$ & 93 & $51 \cdot 4$ & 84 & $44 \cdot 4$ & \\
\hline$\geq 9$ & 145 & $39 \cdot 2$ & 72 & $39 \cdot 8$ & 73 & $38 \cdot 6$ & \\
\hline Monthly family income (MW)‡ & & & & & & & $0 \cdot 213$ \\
\hline$<1$ & 115 & $31 \cdot 1$ & 62 & $34 \cdot 3$ & 53 & $28 \cdot 0$ & \\
\hline $1-3$ & 177 & $47 \cdot 8$ & 87 & $48 \cdot 1$ & 90 & $47 \cdot 6$ & \\
\hline$>3$ & 78 & $21 \cdot 1$ & 32 & $17 \cdot 7$ & 46 & $24 \cdot 3$ & \\
\hline Parity & & & & & & & $<0.001$ \\
\hline Primiparous & 156 & $42 \cdot 2$ & 99 & $54 \cdot 7$ & 57 & $30 \cdot 2$ & \\
\hline Multiparous & 214 & $57 \cdot 8$ & 82 & $45 \cdot 3$ & 132 & $69 \cdot 8$ & \\
\hline Marital status & & & & & & & $0 \cdot 021$ \\
\hline Married & 77 & $20 \cdot 8$ & 28 & $15 \cdot 5$ & 49 & $25 \cdot 9$ & \\
\hline Living with the partner & 214 & $57 \cdot 8$ & 107 & $59 \cdot 1$ & 107 & $56 \cdot 6$ & \\
\hline Single/separated/divorced & 79 & $21 \cdot 4$ & 46 & $25 \cdot 4$ & 33 & $17 \cdot 5$ & \\
\hline Smoking & & & & & & & 0.924 \\
\hline Yes & 101 & $27 \cdot 3$ & 49 & $27 \cdot 1$ & 52 & $27 \cdot 5$ & \\
\hline No & 269 & $72 \cdot 7$ & 132 & $72 \cdot 9$ & 137 & $72 \cdot 5$ & \\
\hline Breast-feeding & & & & & & & 0.690 \\
\hline No & 88 & $23 \cdot 8$ & 40 & $22 \cdot 1$ & 48 & $25 \cdot 4$ & \\
\hline Non-exclusive & 221 & $59 \cdot 7$ & 112 & $61 \cdot 9$ & 109 & $57 \cdot 7$ & \\
\hline Exclusive & 61 & $16 \cdot 5$ & 29 & $16 \cdot 0$ & 32 & $16 \cdot 9$ & \\
\hline Pre-pregnancy BMI $\left(\mathrm{kg} / \mathrm{m}^{2}\right)$ & & & & & & & $<0.001$ \\
\hline$<18.5$ & 17 & $4 \cdot 6$ & 17 & $9 \cdot 4$ & 0 & 0.0 & \\
\hline $18 \cdot 5-24 \cdot 9$ & 224 & $60 \cdot 5$ & 155 & $85 \cdot 6$ & 69 & $36 \cdot 5$ & \\
\hline $25 \cdot 0-29 \cdot 9$ & 78 & $21 \cdot 1$ & 4 & $2 \cdot 2$ & 74 & $39 \cdot 2$ & \\
\hline$\geq 30 \cdot 0$ & 51 & $13 \cdot 8$ & 5 & $2 \cdot 8$ & 46 & $24 \cdot 3$ & \\
\hline Gestational weight gain§ & & & & & & & $<0.001$ \\
\hline Insufficient & 87 & 23.5 & 66 & $36 \cdot 5$ & 21 & $11 \cdot 1$ & \\
\hline Adequate & 106 & $28 \cdot 6$ & 60 & $33 \cdot 1$ & 46 & $24 \cdot 3$ & \\
\hline Excessive & 177 & $47 \cdot 8$ & 55 & $30 \cdot 4$ & 122 & $64 \cdot 6$ & \\
\hline Fibre intakell & & & & & & & 0.018 \\
\hline Below recommendations & 85 & $23 \cdot 0$ & 32 & $17 \cdot 7$ & 53 & $28 \cdot 0$ & \\
\hline According to recommendations & 285 & $77 \cdot 0$ & 149 & $82 \cdot 3$ & 136 & $72 \cdot 0$ & \\
\hline White rice $(\mathrm{g} / \mathrm{d})$ & & & & & & & 0.449 \\
\hline 1st quartile $(49 \cdot 7,19 \cdot 2)$ & 76 & $20 \cdot 5$ & 34 & $18 \cdot 8$ & 42 & $22 \cdot 2$ & \\
\hline 4th quartile $(237 \cdot 1,59 \cdot 0)$ & 99 & $26 \cdot 8$ & 50 & $27 \cdot 6$ & 49 & $25 \cdot \overline{9}$ & \\
\hline Beans $(g / d)$ & & & & & & & 0.034 \\
\hline 1st quartile $(31 \cdot 6,24 \cdot 9)$ & 92 & $24 \cdot 9$ & 42 & $23 \cdot 2$ & 50 & $26 \cdot 5$ & \\
\hline 4th quartile $(620 \cdot 5,375 \cdot 6)$ & 81 & $21 \cdot 9$ & 50 & $27 \cdot 6$ & 31 & $16 \cdot 4$ & \\
\hline White bread $(\mathrm{g} / \mathrm{d})$ & & & & & & & 0.289 \\
\hline 1st quartile $(22 \cdot 54,21 \cdot 5)$ & 102 & $27 \cdot 6$ & 48 & $26 \cdot 5$ & 54 & $28 \cdot 6$ & \\
\hline 4th quartile $(345 \cdot 2,88 \cdot 7)$ & 63 & $17 \cdot 0$ & 35 & $19 \cdot 3$ & 28 & $14 \cdot 8$ & \\
\hline Energy consumption $\|$ & & & & & & & 0.066 \\
\hline Below recommendations & 161 & 43.5 & 70 & $38 \cdot 7$ & 91 & $48 \cdot 1$ & \\
\hline According to recommendations & 209 & $56 \cdot 5$ & 111 & $61 \cdot 3$ & 98 & 51.9 & \\
\hline Postpartum follow-up time & & & & & & & 0.930 \\
\hline 4 months & 157 & $42 \cdot 5$ & 77 & $42 \cdot 8$ & 80 & $42 \cdot 3$ & \\
\hline $5-6$ months & 212 & $57 \cdot 5$ & 103 & $57 \cdot 2$ & 109 & $57 \cdot 6$ & \\
\hline
\end{tabular}

*Obesity risk - evolution of BMI from pre-pregnancy to 4th-6th month postpartum: change from a normal weight pre-pregnancy to overweight or obesity in postpartum, from overweight pre-pregnancy to obesity in postpartum, from class I obesity pre-pregnancy to class II obesity in postpartum, from class II obesity pre-pregnancy to class III obesity in postpartum, weight gain among women who reported pre-pregnancy overweight or obese but not enough to alter nutritional status in postpartum, weight loss among women who reported pre-pregnancy overweight or obesity but not enough to alter nutritional status in postpartum.

tPearson's $\chi^{2}$ test.

$\ddagger \mathrm{MW}=$ minimum wages (equivalent to $\$$ US $175 /$ month).

$\S$ Total gestational weight gain classification according to the US Institute of Medicine (2009) ${ }^{(9)}$.

$\|$ Fibre or energy recommendations according to Dietary Reference Intakes, considering breast-feeding or non-breast-feeding women (Institute of Medicine $(2005)^{(23)}$ and American Dietetic Association (2008) $\left.{ }^{(13)}\right)$.

TThirteen per cent of the sample were interviewed at the beginning of the sixth postpartum month. 
were kept in the final model. Results were described as relative risks (RR) and 95\% confidence intervals. The SPSS statistical software package version 18 was used.

\section{Results}

Mean age of participants was $24 \cdot 8$ (SD $6 \cdot 0$ ) years, average schooling was $7 \cdot 7$ (SD 2.8) years and average monthly family income was \$US $430 \cdot 7$ (sD \$US 338.3). Mean postpartum follow-up time was $4 \cdot 7(0 \cdot 6)$ months and $87 \%$ of the interviews took place until the fifth postpartum month. Average pre-pregnancy BMI was $24 \cdot 4$ (SD $4 \cdot 6) \mathrm{kg} / \mathrm{m}^{2}$ and the total gestational weight gain was $14 \cdot 2(\mathrm{sD} 6 \cdot 2) \mathrm{kg}$. Other social, demographic, behavioural and maternal nutrition features of the total sample, stratified by obesity risk, are described in Table 1 . Variables significantly associated with obesity risk were maternal age, parity, marital status, pre-pregnancy BMI, total gestational weight gain, fibre and bean intakes in phase III (all $P<0 \cdot 001$ except for marital status, fibre and bean intakes, where $P=0 \cdot 021,0 \cdot 018$ and 0.034, respectively; Table 1 ).

Median postpartum maternal weight retention was $4 \cdot 4$ (IQR 0.6, 7·9) kg. Obesity risk incidence, according to BMI evolution in the postpartum period ( $n$ 189), was $51 \cdot 1 \%(95 \%$ CI $46 \cdot 0,56 \cdot 2 \%)$. Figure 2 shows cohort participants stratified by obesity risk category.

The median daily energy intake postpartum was 11950 (IQR 9037, 15347 ) kJ/d. The percentage of total energy

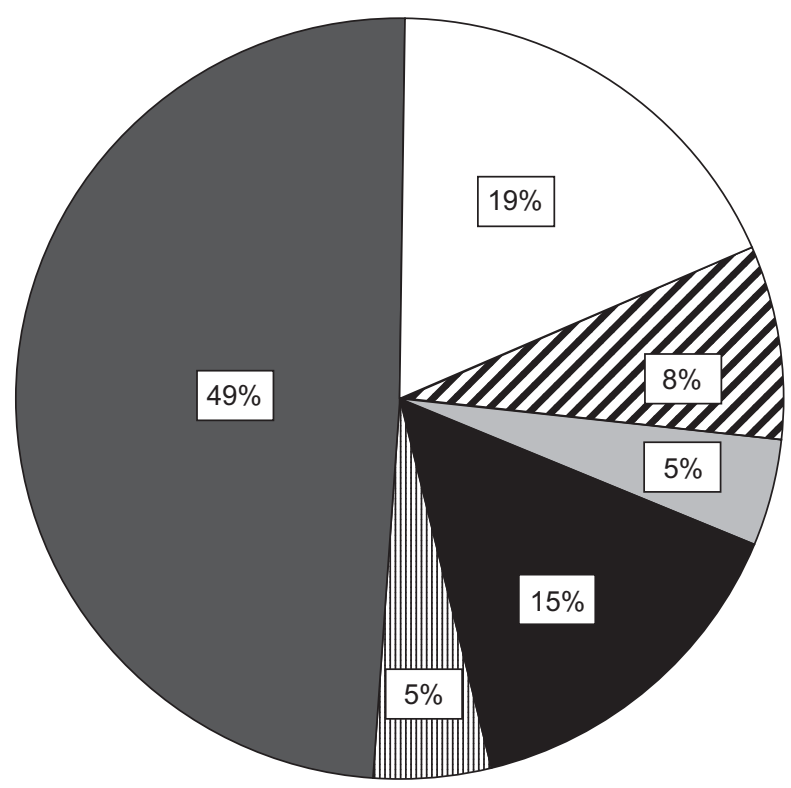

Fig. 2 Change from pre-pregnancy to postpartum in obesity risk category (in clockwise order: $\square$, normal weight to overweight or obesity; 团, overweight to obesity; $\square$, class I obesity to class II obesity; , overweight or obesity with BMI increase without changing category; 四, overweight or obesity with BMI decrease without changing category; $\square$, without obesity risk) among women of two cities in southern Brazil (n 370), ECCAGE cohort study, 2006-2007 intake arising from dietary carbohydrates was $63.6 \%$ (SD 10.1\%); from proteins, $15 \cdot 4 \%$ (SD 2.9\%); and from fats, $23 \cdot 6 \%$ (sD 5.7\%). Median fibre intake was 42 (IQR $28 \cdot 9,55 \cdot 4) \mathrm{g} / \mathrm{d}$, with $77 \%(95 \% \mathrm{CI} 72 \cdot 7,81 \cdot 3 \%)$ ingesting a quantity greater than or equal to the recommended minimum.

Figure 3 represents the FPCA centred on the fibre intake variable, showing the correlations between selected food items in the FFQ and total dietary fibre quantity. Beans were the food that showed the strongest correlation with total fibre in the diet. On another correlation level, bread and rice were found to significantly correlate with fibre in the diet, indicating a common Brazilian food pattern along with beans. Consumption of spices like onion, garlic, tomato and red pepper, food items typically included in the preparation of common Brazilian meals, were also significantly correlated with dietary fibre.

Figure 4 represents the FPCA centred on the postpartum weight retention variable, showing the correlations between total energy value percentages of foods and maternal weight retention. Individual food items did not impact on postpartum weight retention. The only variable with a significant positive correlation was white bread. This figure shows food patterns similar to those of Fig. 3.

Table 2 shows the results for the association between inadequate fibre intake and obesity risk. In the unadjusted model, women who did not reach the daily recommended fibre intake had an obesity risk $30 \%(\mathrm{RR}=1 \cdot 30$; $95 \%$ CI $1 \cdot 06,1 \cdot 60)$ higher than those who did reach the recommended fibre intake. When adjusted for maternal age, pre-pregnancy BMI and weight gain during pregnancy, the association between fibre intake and obesity risk remained significant $(\mathrm{RR}=1 \cdot 24 ; 95 \% \mathrm{CI} 1 \cdot 05,1 \cdot 47)$.

\section{Discussion}

The present study points to a high incidence of obesity risk, as defined by the evolution of maternal pre-pregnancy BMI through the 4th-6th month postpartum. Less than recommended consumption of fibre was associated with this risk. The only specific food item shown to be correlated with postpartum weight retention was white bread, consumption frequency of which was at least twice daily in more than $50 \%$ of the sample. Beans were the food with the greatest daily fibre contribution to the diet, forming a typical Brazilian food pattern together with rice and white bread. Fruits and vegetables formed another consumption pattern. Although representing an important potential source of fibre, they were generally consumed in small quantities and thus showed only a weak correlation with the daily fibre ingestion in the present sample.

The high risk for future obesity occasioned by pregnancy is a cause for concern. Previous evidence shows that excessive weight gain, above the recommendations of the IOM, together with the failure to lose weight during 


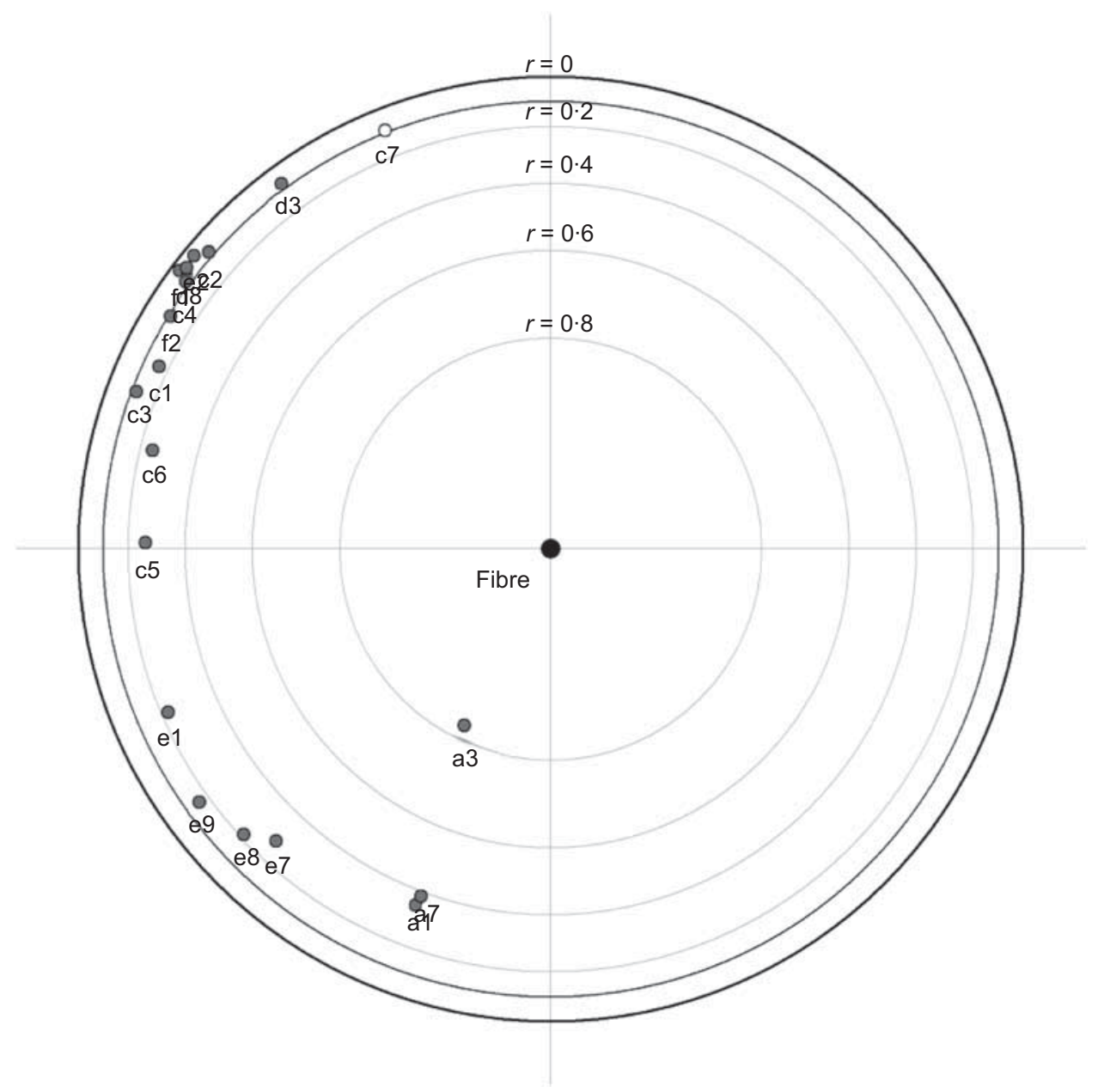

Fig. 3 Correlations of foods ( $\bigcirc$, positive correlation; $\bigcirc$, negative correlation) with total fibre content of the diet: focused principal component analysis among women of two cities in southern Brazil ( $n$ 370), ECCAGE cohort study, 2006-2007. Legend: a1 = rice; a3 = beans; $\mathrm{a} 7=$ bread; $\mathrm{c} 1=$ lentils, $\mathrm{c} 2=$ lettuce, $\mathrm{c} 3=$ kale; $\mathrm{c} 4=$ cabbage, $\mathrm{c} 5=$ orange, $\mathrm{c} 6=$ banana, $\mathrm{c} 7=\mathrm{papaya}, \mathrm{c} 8=\mathrm{apple}$, d3 = mango, e1 = tomato, e2 = chayote, e7 = onion; e8 = garlic, e9 = red pepper; $\mathrm{f} 1$ = carrot, $\mathrm{f} 2$ = sugarbeet

the postpartum period, are important obesity predictors for women of reproductive age ${ }^{(8,38)}$. Recent anthropometric data from the 2008-2009 Family Budget Study are alarming in the sense of demonstrating that weight excess is present in $48 \%$ of the Brazilian female adult population, exceeding the frequency of weight deficit thirteen times. Obesity, present in $16 \cdot 9 \%$ of Brazilian women, corresponds to about one-third of these weight excess cases ${ }^{(39)}$.

The literature indicates excessive gestational weight gain as the main weight retention predictor postpartum $^{(6,7,38,40-42)}$. Nevertheless, some authors stress that the relationship between weight gain during pregnancy and posterior postpartum weight retention may be subject to the 'part-whole' bias, meaning that weight gain is a component of weight retention and pointing to a high correlation between these variables ${ }^{(2)}$.

Weight retention after pregnancy may be physiologically more dangerous than weight changes in other life stages because weight excess retained postpartum seems to deposit preferentially in a central manner, increasing the risk of insulin resistance and of cardiovascular illness ${ }^{(43)}$. Only one previous study reported a protective effect of fibre-rich foods in reducing the risk of postpartum weight retention ${ }^{(1)}$. The present study showed similar results by demonstrating that inadequate fibre consumption increases obesity risk corresponding to an unfavourable BMI evolution postpartum.

An individual analysis of the foods consumed in the postpartum period showed that white bread was the only food significantly correlated with maternal weight retention. To our knowledge, no other study has indicated this association. It is important to underscore the effects of white bread on glycaemic changes, acting as a possible obesity cofactor ${ }^{(44)}$. Foods with a high glycaemic index, like white bread, appear to cause less satiety, more hunger after meals and increase daily energy intake, while foods with a high fibre content have been proposed to be more satiating, reduce hunger and decrease energy intake ${ }^{(45)}$.

When assessing specific food items in relation to their fibre contribution in the sample's diet, beans showed 


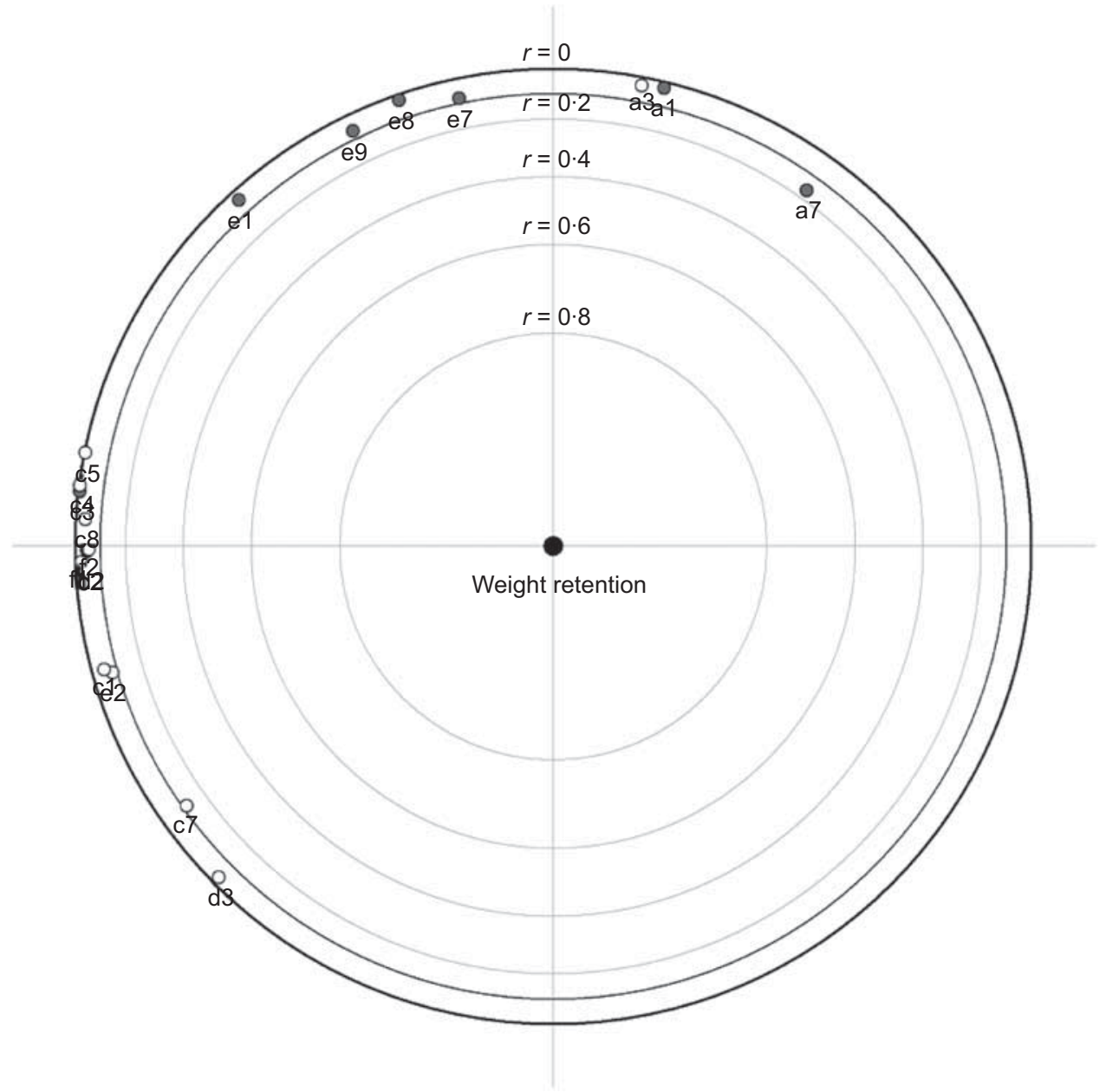

Fig. 4 Correlations of the percentage of total energy intake of given foods (O, positive correlation; $\bigcirc$, negative correlation) with postpartum weight retention: focused principal component analysis among women of two cities in southern Brazil ( $n 370)$, ECCAGE cohort study, 2006-2007. Legend: a1 = rice; a3 = beans; a7 = bread; c1 = lentils, c2 = lettuce, c3 = kale; c4 = cabbage, $\mathrm{c} 5=$ orange, $\mathrm{c} 6=$ banana, $\mathrm{c} 7=$ papaya, $\mathrm{c} 8=$ apple, $\mathrm{d} 3=$ mango, e1 $=$ tomato, $\mathrm{e} 2=$ chayote, e7 $=\mathrm{onion} ; \mathrm{e} 8=\mathrm{garlic}, \mathrm{e} 9=\mathrm{red}$ pepper; $\mathrm{f} 1$ = carrot, $\mathrm{f} 2$ = sugarbeet

Table 2 Association* between fibre intake and obesity risk in postpartum among women of two cities in southern Brazil ( $n$ 370), ECCAGE cohort study, 2006-2007

\begin{tabular}{|c|c|c|c|c|c|c|}
\hline \multirow[b]{2}{*}{ Fibre intake } & \multicolumn{2}{|c|}{ Crude analysis } & \multicolumn{2}{|c|}{ Model 1} & \multicolumn{2}{|c|}{ Model 2} \\
\hline & $\mathrm{RR}$ & $95 \% \mathrm{Cl}$ & $\mathrm{RR}$ & $95 \% \mathrm{Cl}$ & $\mathrm{RR}$ & $95 \% \mathrm{Cl}$ \\
\hline Below recommendationst & $1 \cdot 30$ & $1 \cdot 06,1 \cdot 60$ & $1 \cdot 32$ & $1 \cdot 10,1 \cdot 60$ & $1 \cdot 24$ & $1 \cdot 05,1 \cdot 47$ \\
\hline Within recommendations & 1.00 & Ref. & $1 \cdot 00$ & Ref. & $1 \cdot 00$ & Ref. \\
\hline
\end{tabular}

Ref., referent category.

Model 1: adjusted for to maternal age, pre-pregnancy BMI. Model 2: Model $1+$ total gestational weight gain.

${ }^{*}$ Adjusted through Poisson regression models with robust variance.

†According to Dietary Reference Intakes (Institute of Medicine (2005) ${ }^{(23)}$ and American Dietetic Association (2008) ${ }^{(13)}$ ).

the strongest association. This finding confirms previous evidence that indicates beans as a primary fibre source in the typical Brazilian diet among adults. Of note, beans are also an important source of $\mathrm{Fe}$ and, when associated with rice, combine to represent a source of high-quality plant protein, commonly referred to as the 'perfect protein'(28).
This typical Brazilian eating pattern associated with fibre intake, identified in the present is study, gave the greatest fibre contribution to the postpartum diet, highlighting the minimal consumption of fruits and vegetables in this lowincome population. Both national and international studies underscore the association between low income and the high consumption of beans, along with low consumption 
of fruits and vegetables ${ }^{(28,46-49)}$. Nevertheless, our findings do not allow comparisons between the reported patterns and different income ranges, due to the homogeneity of our sample regarding income.

Among the limitations of the present study we can mention the inclusion of adolescent pregnant women, which may reduce the estimates' validity since these women are still going through a developmental stage. The lack of data on body fat percentage and physical activity is another limitation since these are relevant factors associated with postpartum weight retention ${ }^{(1,50)}$. Regarding the assessment of food consumption, the limited ability of the FFQ to estimate real intake, as characterized in a relative validity study comparing FFQ and $24 \mathrm{~h}$ dietary recalls ${ }^{(29)}$, is another limitation. Furthermore, lactating women may overestimate food consumption $^{(51-53)}$. Another limitation is the use of reported, rather than measured, pre-pregnancy weight. However, studies indicate a high correlation between referred and measured weight ${ }^{(4,54-57)}$.

Keeping in mind the above mentioned limitations, the present study, the first to our knowledge in the Brazilian context, suggests that protection against maternal weight excess in the 4th-6th month after childbirth may be viable by reaching the daily values of recommended fibre intake, choosing the typical Brazilian dietary pattern that is characterized by a high fibre content, especially due to beans consumption. It is important to note that the current belief (built up mainly by the media) that a healthy diet is expensive and necessarily quite different from the usual one, is mistaken ${ }^{(58)}$.

The risk of obesity in women in reproductive age is concerning. If dietary fibre can be a modifiable factor related to weight control postpartum, then public policies focusing on interventions for this specific population should be put into practice. Commitment of the government and of the public sector is essential to encourage, support and protect healthy eating. The publication of an addendum in the Food Guide for the Brazilian Population, including a specific topic with recommendations regarding pregnancy and postpartum, is of utmost importance, since this stage of life represents a good opportunity for nutritional education ${ }^{(42)}$. Maternal nutrition not only influences birth outcomes but ultimately impacts on the long-term health status of the offspring ${ }^{(59-61)}$.

\section{Conclusions}

Obesity risk related to weight gain or retention in the postpartum period was shown to be high in this sample of southern Brazilian women and represents a major public health concern given the ongoing obesity epidemic. Fibre intake appears to reduce the risk of an even worse situation. In this population, the main fibre source is associated with the typical Brazilian meal, especially with bean consumption. In this sense, the revival of traditional food practices as well as the consumption of healthy regional food, considering the cultural identity, behavioural and affective aspects, should be encouraged.

\section{Acknowledgments}

Sources of funding: The research was financed by the Programa de Apoio a Núcleos de Excelência (PRONEX) and Coordenação de Aperfeiçoamento de Pessoal de Nivel Superior (CAPES). Conflicts of interest: There is no financial conflict of interest for all authors. The authors have no undisclosed financial or personal interest in any company or organization connected in any way with the research represented herein. Authors' contributions: The data reported in this paper were collected as part of the first author's PhD thesis that was supervised by M.I.S. and S.A.C. All authors were responsible for the design and performance of the ECCAGE Study. M.A.N. designed the research (project conception, development of overall research plan, study oversight), interpretation of data and critical review of the manuscript. M.L. contributed to analysis and interpretation of the data and preparation of the manuscript. B.B.D. and A.P.P. critically reviewed the manuscript. All authors have read and approved the final manuscript.

\section{References}

1. Oken E, Taveras EM, Popoola FA et al. (2007) Television, walking, and diet: associations with postpartum weight retention. Am J Prev Med 32, 305-311.

2. Lacerda E \& Leal MC (2004) Risk factors associated with postpartum weight gain and retention: a systematic review. Rev Bras Epidemiol 7, 187-200.

3. Kac G, Benicio MH, Velasquez-Melendez G et al. (2004) Gestational weight gain and prepregnancy weight influence postpartum weight retention in a cohort of Brazilian women. J Nutr 134, 661-666.

4. Gunderson EP, Abrams B \& Selvin S (2000) The relative importance of gestational gain and maternal characteristics associated with the risk of becoming overweight after pregnancy. Int J Obes Relat Metab Disord 24, $1660-1668$.

5. Ohlin A \& Rossner S (1994) Trends in eating patterns, physical activity and socio-demographic factors in relation to postpartum body weight development. BrJ Nutr 71, 457-470.

6. Olson CM, Strawderman MS, Hinton PS et al. (2003) Gestational weight gain and postpartum behaviors associated with weight change from early pregnancy to $1 \mathrm{y}$ postpartum. Int J Obes Relat Metab Disord 27, 117-127.

7. Althuizen E, van Poppel MN, Seidell JC et al. (2006) Design of the New Life(style) study: a randomised controlled trial to optimise maternal weight development during pregnancy. BMC Public Health 6, 168.

8. Siega-Riz AM, Viswanathan M, Moos MK et al. (2009) A systematic review of outcomes of maternal weight gain according to the Institute of Medicine recommendations: birthweight, fetal growth, and postpartum weight retention. Am J Obstet Gynecol 201, 339.e1-339.e14. 
9. Rasmussen KM \& Yaktine AL (editors) (2009) Weight Gain During Pregnancy: Reexamining the Guidelines. Washington, DC: National Academies Press.

10. Castro MBT, Kac G \& Sichieri R (2009) Determinantes nutricionais e sóciodemográficos da variação do peso no pós-parto: uma revisão da literatura. Rev Bras Saude Matern Infant 9, 125-137.

11. Linne Y \& Rossner S (2003) Interrelationships between weight development and weight retention in subsequent pregnancies: the SPAWN study. Acta Obstet Gynecol Scand 82, 318-325.

12. Kinnunen TI, Pasanen M, Aittasalo M et al. (2007) Reducing postpartum weight retention - a pilot trial in primary health care. Nutr J 6, 21.

13. American Dietetic Association (2008) Position of the American Dietetic Association: nutrition and lifestyle for a healthy pregnancy outcome. J Am Diet Assoc 108, 553-561.

14. Subcommittee for a Clinical Applications Guide, Institute of Medicine, National Academy of Sciences (1992) Nutrition During Pregnancy and Lactation: An Implementation Guide. Washington, DC: National Academies Press.

15. Kac G, Benicio MH, Velasquez-Melendez G et al. (2004) Nine months postpartum weight retention predictors for Brazilian women. Public Health Nutr 7, 621-628.

16. Gunderson EP \& Abrams B (1999) Epidemiology of gestational weight gain and body weight changes after pregnancy. Epidemiol Rev 21, 261-275.

17. Gunderson EP (2009) Childbearing and obesity in women: weight before, during, and after pregnancy. Obstet Gynecol Clin North Am 36, 317-332.

18. Walker LO, Sterling BS \& Timmerman GM (2005) Retention of pregnancy-related weight in the early postpartum period: implications for women's health services. J Obstet Gynecol Neonatal Nurs 34, 418-427.

19. Castro MBT, Kac G, de Leon AP et al. (2009) High-protein diet promotes a moderate postpartum weight loss in a prospective cohort of Brazilian women. Nutrition 25, $1120-1128$.

20. Lindstrom J, Peltonen M, Eriksson JG et al. (2006) Highfibre, low-fat diet predicts long-term weight loss and decreased type 2 diabetes risk: the Finnish Diabetes Prevention Study. Diabetologia 49, 912-920.

21. American Dietetic Association (1997) Position of the American Dietetic Association: health implications of dietary fiber. J Am Diet Assoc 97, 1157-1159.

22. Bhargava A (2006) Fiber intakes and anthropometric measures are predictors of circulating hormone, triglyceride, and cholesterol concentrations in the women's health trial. J Nutr 136, 2249-2254.

23. Institute of Medicine, Food and Nutrition Board (2005) Dietary Reference Intakes for Energy, Carbohydrate, Fiber, Fat, Fatty Acids, Cholesterol, Protein, and Amino Acids. Washington, DC: The National Academies Press.

24. World Health Organization (2003) Diet, Nutrition and the Prevention of Chronic Disease. Joint FAO/WHO Expert Consultation. WHO Technical Report Series no. 916. Geneva: WHO.

25. Swinburn BA, Caterson I, Seidell JC et al. (2004) Diet, nutrition and the prevention of excess weight gain and obesity. Public Health Nutr 7, 123-146.

26. Nunes MA, Ferri C, Manzoli P et al. (2010) Nutrition, mental health and violence: from pregnancy to postpartum cohort of women attending primary care units in southern Brazil SCDBP. BMC Psychol 10, 66.

27. Buss C, Nunes MA, Camey S et al. (2009) Dietary fibre intake of pregnant women attending general practices in southern Brazil - the SCDBP Study. Public Health Nutr 12, 1392-1398.

28. Ministério da Saúde (2006) Guia Alimentar para a População Brasileira. Brasília: Ministério da Saúde.
29. Giacomello A, Schmidt MI, Nunes MAA et al. (2008) Validação relativa de Questionário de frequência alimentar em gestantes usuárias de serviços do Sistema Único de Saúde em dois municípios no Rio Grande do Sul, Brasil. Rev Bras Saude Matern Infant 8, 445-454.

30. Zulkifli SN \& Yu SM (1992) The food frequency method for dietary assessment. J Am Diet Assoc 92, 681-685.

31. Willett W (1998) Nutritional Epidemiology, 2nd ed. New York: Oxford University Press.

32. Pinheiro A (2004) Tabela para avaliação de consumo alimentar em medidas caseiras. São Paulo: Atheneu.

33. Department de Foods e Nutrition Experimental da Faculdade de Ciências Farmacêuticas - USP (2007) Tabela Brasileira de Composição de Alimentos. http://www.fcf.usp.br/tabela (accessed February 2012).

34. Philippi ST (2002) Tabela de Composição de Alimentos: Suporte para Decisão Nutricional, 2 ed. São Paulo: Coronário.

35. Drehmer M, Camey S, Schmidt MI et al. (2010) Socioeconomic, demographic and nutritional factors associated with maternal weight gain in general practices in Southern Brazil. Cad Saude Publica 26, 1024-1034.

36. Falissard B, Corruble E, Mallet L et al. (2001) Focused principal component analysis: a promising approach for confirming findings of exploratory analysis? Int J Methods Psychiatr Res 10, 191-195.

37. Canuto R, Camey S, Gigante D et al. (2010) Focused principal component analysis: a graphical method for exploring dietary patterns. Cad Saude Publica 26, 2149-2156.

38. Rooney BL \& Schauberger CW (2002) Excess pregnancy weight gain and long-term obesity: one decade later. Obstet Gynecol 100, 245-252.

39. Ministério da Saúde \& Ministério do Planejamento, Orçamento e Gestão (2010) Pesquisa de Orçamentos Familiares 2008-2009. Antropometria e estado nutricional de crianças, adolescentes e adultos do Brasil. Rio de Janeiro: Instituto Brasileiro de Geografia e Estatística.

40. Scholl TO, Hediger ML, Schall JI et al. (1995) Gestational weight gain, pregnancy outcome, and postpartum weight retention. Obstet Gynecol 86, 423-427.

41. Gunderson EP \& Abrams B (1999) Epidemiology of gestational weight gain and body weight changes after pregnancy. Epidemiol Rev 21, 261-275.

42. Phelan S (2010) Pregnancy: a teachable moment for weight control and obesity prevention. Am J Obstet Gynecol 202, e1-e8.

43. Gunderson EP, Murtaugh MA, Lewis CE et al. (2004) Excess gains in weight and waist circumference associated with childbearing: The Coronary Artery Risk Development in Young Adults Study (CARDIA). Int J Obes Relat Metab Disord 28, 525-535.

44. van Bakel MME, Kaaks R, Feskens EJM et al. (2009) Dietary glycaemic index and glycaemic load in the European Prospective Investigation into Cancer and Nutrition. Eur J Clin Nutr 63, Suppl. 4, S188-S205.

45. Rolls JB, Ello-Martin JA \& Tohill BC (2004) What can intervention studies tell us about the relationship between fruit and vegetable consumption and weight management? Nutr Rev 62, 1-17.

46. Monteiro CA, Mondini L \& Costa RB (2000) Changes in composition and appropriate nutrition of family diet in the metropolitan areas of Brazil (1988-1996). Rev Saude Publica 34, 251-258.

47. Ministério da Saúde (2009) Indicadores de Vigilância Alimentar e Nutricional Brasil 2006. Série B. Textos Básicos de Saúde. Brasília: Ministério da Saúde.

48. Caire-Juvera G, Ortega MI, Casanueva E et al. (2007) Food components and dietary patterns of two different groups of Mexican lactating women. J Am Coll Nutr 26, 156-162. 
49. Mitchell DC, Lawrence FR, Hartman TJ et al. (2009) Consumption of dry beans, peas, and lentils could improve diet quality in the US population. J Am Diet Assoc 109, 909-913.

50. Amorim AR, Lacerda E \& Kac G (2007) Uso e interpretação dos indicadores antropométricos na avaliação do Estado Nutricional de Gestantes. In Epidemiologia Nutricional, pp. 31-47 [G Kac, R Sichieri and DP Gigante editors]. Rio de Janeiro: Atheneu.

51. Forsythe HE \& Gage B (1994) Use of a multicultural foodfrequency questionnaire with pregnant and lactating women. Am J Clin Nutr 59, 1 Suppl., 203S-206S.

52. Erkkola M, Karppinen M, Javanainen J et al. (2001) Validity and reproducibility of a food frequency questionnaire for pregnant Finnish women. Am J Epidemiol 154, 466-476.

53. Baer HJ, Blum RE, Rockett HR et al. (2005) Use of a food frequency questionnaire in American Indian and Caucasian pregnant women: a validation study. BMC Public Health 5, 135.

54. Abrams B, Carmichael S \& Selvin S (1995) Factors associated with the pattern of maternal weight gain during pregnancy. Obstet Gynecol 86, 170-176.
55. Kleinman KP, Oken E, Radesky JS et al. (2007) How should gestational weight gain be assessed? A comparison of existing methods and a novel method, area under the weight gain curve. Int J Epidemiol 36, 1275-1282.

56. Nucci L, Duncan B, Mengue S et al. (2001) Assessment of weight gain during pregnancy in general prenatal care services in Brazil. Cad Saude Publica 17, 1367-1374.

57. Schmidt MI, Duncan BB, Tavares M et al. (1993) Validity of self-reported weight - a study of urban Brazilian adults. Rev Saude Publica 27, 271-276.

58. Ministério da Saúde, Coordenação-Geral da Política de Alimentação e Nutrição (2005) O que é uma alimentação saudâvel? Considerações sobre o conceito, princípios $e$ características: uma abordagem ampliada. Brasilia: Ministério da Saúde.

59. Oken E \& Gillman MW (2003) Fetal origins of obesity. Obes Res 11, 496-506.

60. Oken E, Taveras EM, Kleinman KP et al. (2007) Gestational weight gain and child adiposity at age 3 years. Am J Obstet Gynecol 196, e1-e8.

61. Salsberry PJ \& Reagan PB (2005) Dynamics of early childhood overweight. Pediatrics 116, 1329-1338. 